TECHNICAL NOTE

\author{
T.N. Nguyen \\ S. Lanthier \\ D. Roy
}

\section{latrogenic Arterial Perforation during Acute Stroke Interventions}

SUMMARY: Arterial perforation is a feared complication of acute stroke intervention. A high index of suspicion is important to recognize this complication and tailor patient management to prevent further deterioration in clinical outcome. This report describes the endovascular management of microcatheter arterial perforation in a 66-year-old woman with an acute left middle cerebral artery stroke. The microcatheter was retained in the patient to seal the perforated site, resulting in good outcome at 3-month follow-up.
W ith the increasing use of intra-arterial interventions for acute ischemic stroke, an inevitable parallel rise in technical complications ensues. Arterial perforation is one of the unexpected and feared complications, occurring in 1\% to $9 \%$ of intraarterial interventions and can be fatal. ${ }^{1-4}$ In the pooled results of the MERCI and multi-MERCI trials, vessel perforation occurred in $3(3.8 \%)$ of 80 patients undergoing recanalization for acute stroke, resulting in symptomatic hemorrhage and death. ${ }^{1}$ In the IMS study, there were 3 suspected vessel perforations of 80 patients undergoing combined intravenous/intra-arterial recanalization for acute stroke, which resulted in asymptomatic hemorrhage. ${ }^{2}$ A high index of suspicion is important to immediately recognize this complication and tailor patient management to prevent further deterioration in clinical outcome. This report describes the medical and endovascular management of microcatheter arterial perforation in a 66-year-old woman with an acute left middle cerebral artery stroke.

\section{Case Report}

A 66-year-old right-handed woman presented with dysarthria and right hemiparesis with a National Institutes of Health Stroke Scale score of 10, close to 3 hours from onset of symptoms. There was a hyperattenuated left middle cerebral artery on CT. An intravenous tPA bolus $(9 \mathrm{mg})$ was given at 2:58 from onset of symptoms, followed by an intravenous infusion. An intravenous intra-arterial bridging procedure was envisioned. Angiography revealed occlusion of the M1 segment of the left middle cerebral artery with good pial collaterals (Fig 1A).

Intervention. After placement of a $7 \mathrm{~F}$ guide catheter, the M1 occlusion was traversed with a Merci (Concentric Medical, Mountain View, Calif) microcatheter over a 0.014-inch microguidewire. Some resistance was encountered to pass the clot, and the microcatheter was observed on fluoroscopy to take a straight trajectory outside the confines of the middle cerebral artery. A microcatheter injection revealed contrast extravasation into the subarachnoid space, confirming vessel perforation (Fig 1B). Intravenous tPA was immediately stopped at 3:28. There was no gross change on the patient's examination and vital signs. Cryoprecipitate $18 \mathrm{U}$ and 6 bags of platelets were administered. A control angiogram, via the guide catheter, revealed no contrast extravasation, suggesting seal of the perforated vessel with the microcatheter (Fig 1C).

Received July 30, 2007; accepted after revision August 20.

From the Department of Neurology, Neurosurgery, Radiology (T.N.N.), Boston University Medical Center, Boston, Mass; and the Neurology Service (S.L.) and Department of Radiology (D.R.), Notre Dame Hospital, Montreal, Quebec, Canada.

Please address correspondence to Thanh N. Nguyen, MD, Assistant Professor, Neurology, Neurosurgery, Radiology, Boston University Medical Center, 715 Albany St C-329, Boston, MA 02118; e-mail: thanh.nguyen@bmc.org

DOI 10.3174/ajnr.A0958
The safest intervention thought was to leave the microcatheter in the patient to seal the perforated site. The patient was intubated to assure maximum immobility. The microcatheter was cut at its junction with the guide catheter. We removed the guide catheter, while pushing on the proximal end of the microcatheter with a $4 \mathrm{~F}$ catheter to avoid traction on the microcatheter. The microcatheter was cut at its junction with the $7 \mathrm{~F}$ sheath. Via the sheath, the remaining distal end of the microcatheter was pushed with a guidewire into the right femoral artery. Immediate head CT showed contrast extravasation in the left hemisphere subarachnoid space (Fig. 2).

The patient was extubated 48 hours after the procedure. There was no change in her neurologic examination compared with her examination on admission. She was given aspirin indefinitely. Neurologic examination at 3 months revealed preserved language, dysarthria, mild right hemiparesis, and sensory deficit, corresponding to a National Institutes of Health Stroke Scale score of 4. CT angiography at 1 month revealed absence of pseudoaneurysm (Fig 3).

\section{Discussion}

This report describes the management of a patient who underwent attempted intra-arterial revascularization for acute ischemic stroke complicated by microcatheter arterial perforation. The best management of this complication is unknown. When confronted with this complication, the important initial step is to resist the reflex temptation to withdraw the microcatheter that caused the perforation. Premature withdrawal of the microcatheter could result in subarachnoid hemorrhage, potentially exacerbated by the preexisting use of thrombolytics or heparin. Leaving the microcatheter permanently in place can be regarded as a management option that minimizes this risk. When present, a thrombus proximal to the site of perforation likely protects the patient from hemorrhage.

The long-term outcome of patients with retained microcatheters is not well characterized. This complication is more commonly encountered in patients who undergo embolization of an arteriovenous malformation (AVM) in which the microcatheter is inadvertently glued into a feeding artery. ${ }^{5,6}$ In Debrun et al's ${ }^{5}$ series of AVM embolizations, this complication occurred in $3.1 \%$ of feeding artery embolizations in 233 patients, with a related neurologic deficit in 2 patients. Arterial injury by the microcatheter may elicit an inflammatory response within the endothelium and accelerate atherosclerosis. ${ }^{7}$ In turn, this may cause long-term complications such as pseudoaneurysm in the common femoral artery ${ }^{8}$ and thromboembolism, reported as long as 16 months after the event. ${ }^{7}$ Indefinite antithrombotic therapy is indicated for secondary stroke prevention from the presence of a foreign body. 

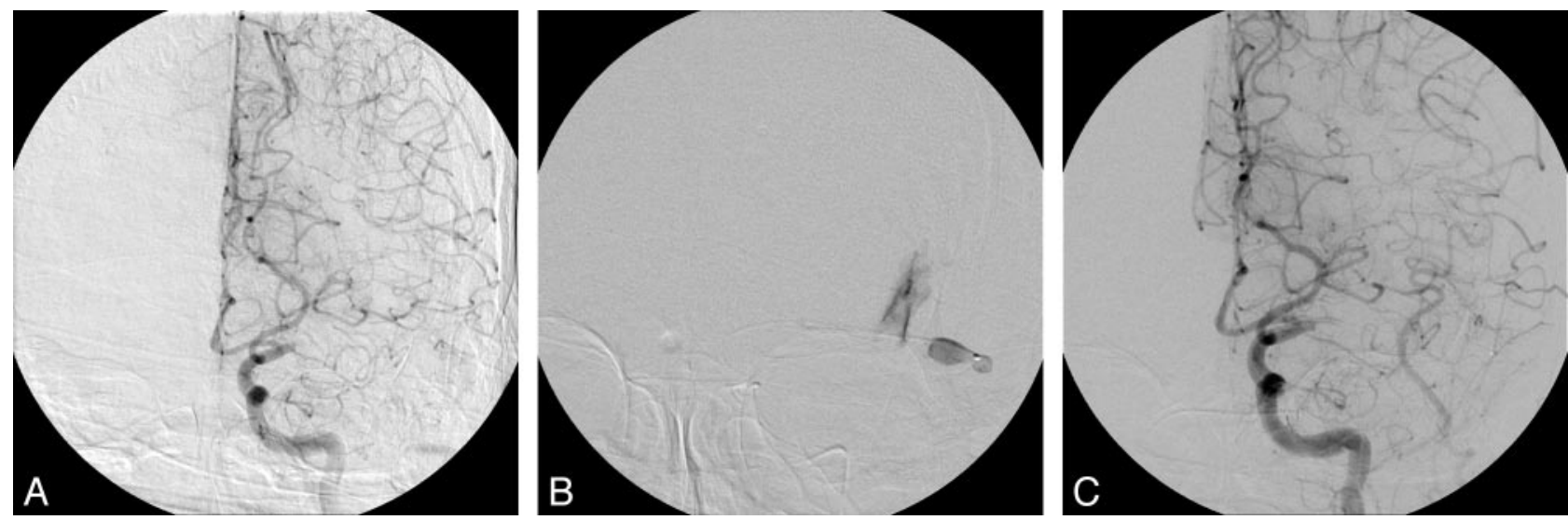

Fig 1. $A-C$, Anteroposterior view of the left common carotid artery with occlusion of the left M1 $(A)$ with pial collaterals. After passing the clot, anteroposterior view of microcathete injection (B), showing contrast extravasation in the subarachnoid space. (C) After microcatheter perforation, left internal carotid artery injection, showing absence of contrast extravasation.

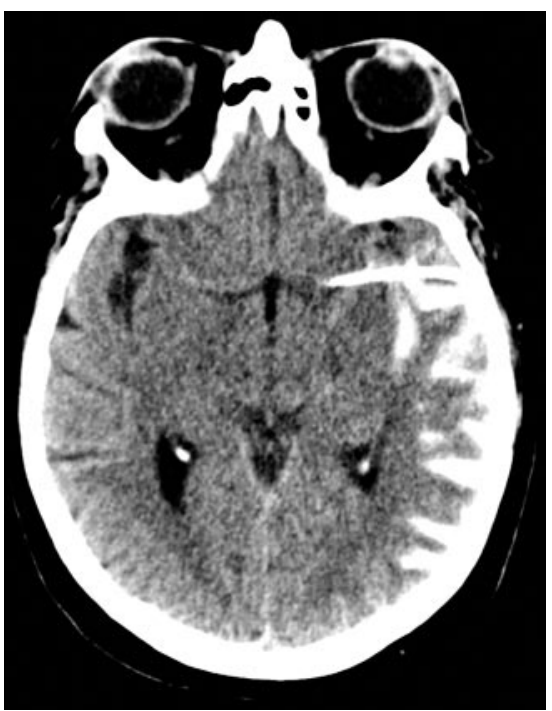

Fig 2. Immediate CT showing contrast extravasation into the subarachnoid space.

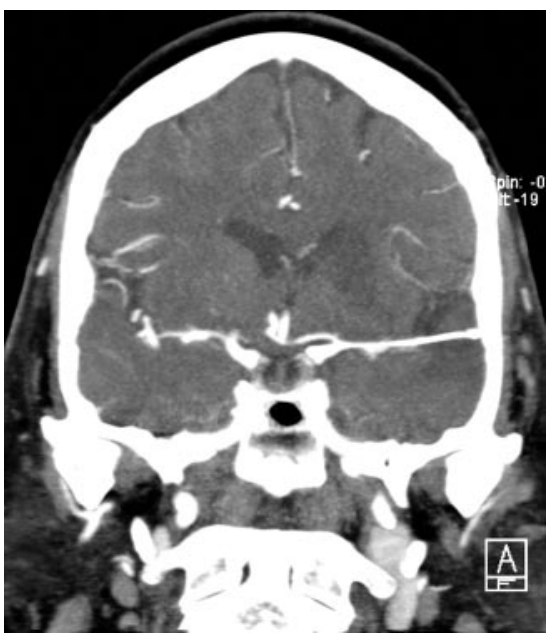

Fig 3. CT angiography at 1 month, showing microcatheter in place and no pseudoaneurysm.

Other management options of arterial perforation include medical, endovascular, and neurosurgical means. All ongoing thrombolytics or anticoagulants should be stopped or reversed. Endovascular options include coiling or gluing the perforated site in the vessel wall, ${ }^{4}$ but this necessitates withdrawal of the microcatheter from the perforated site. Further manipulation of the microcatheter could tear the arterial wall and result in uncontrolled hemostasis. The other difficulty with coiling or gluing the perforated site is that the exact location and extent of rupture may not be well defined on angiography. Neurosurgical trapping of the perforated site could be considered and has been described with microcatheter perforation during an AVM embolization. ${ }^{9}$ Transferring the patient to the operative suite in the setting of a large acute stroke with new subarachnoid hemorrhage is probably associated with high risks for complications because of the mobility required with transfer and risk of dislodging the microcatheter.

\section{Conclusion}

After identification of microcatheter arterial perforation in an acute ischemic stroke, leaving the microcatheter in place could be considered an option and may be life saving. In our opinion, indefinite antiplatelet therapy is indicated because of the presence of a foreign body. Short-term radiographic follow-up is necessary to study for potential complications such as pseudoaneurysm at the site of perforation, and long-term clinical follow-up is important to survey thromboembolic complications.

\section{References}

1. Flint AC, Duckwiler GR, Budzik RF, et al. Mechanical thrombectomy of intracranial internal carotid occlusion: pooled results of the MERCI and Multi MERCI Part I trials. Stroke 2007;38:1274-80

2. IMS Study Investigators. Combined intravenous and intra-arterial recanalization for acute ischemic stroke: the Interventional Management of Stroke Study. Stroke 2004;35:904-11

3. Sorimachi T, Fujii Y, Tsuchiya N, et al. Recanalization by mechanical embolus disruption during intra-arterial thrombolysis in the carotid territory. AJNR Am J Neuroradiol 2004;25:1391-402

4. Halbach VV, Higashida RT, Dowd CF, et al. Management of vascular perforations that occur during neurointerventional procedures. AJNR Am J Neuroradiol 1991;12:319-27

5. Debrun GM, Aletich VA, Shownkeen H, et al. Glued catheters during embolization of brain AVMs with acrylic glue. Int Neuroradiol 1997;3:13-19

6. Frizzel RT, Fisher WS 3rd. Cure, morbidity, and mortality associated with embolization of brain arteriovenous malformations: a review of 1246 patients in 32 series over a 35-year period. Neurosurgery 1995;37:1031-39; discussion 1039-40

7. Zoarski GH, Lilly MP, Sperling JS, et al. Surgically confirmed incorporation of a chronically retained neurointerventional microcatheter in the carotid artery. AJNR Am J Neuroradiol 1999;20:177-78

8. Bingöl H, Sirin G, Akay HT, et al. Management of a retained catheter in an arteriovenous malformation. Case report. J Neurosurg 2007;106:481-83

9. Purdy PD, Batjer HH, Samson D. Management of hemorrhagic complications from preoperative embolization of arteriovenous malformations. J Neurosurg 1991;74:205-11 